Western North American Naturalist 68(2), (C) 2008, pp. 257-259

\title{
CAUDAL MOVEMENTS IN WESTERN FENCE LIZARDS (SCELOPORUS OCCIDENTALIS) PRIOR TO ATTEMPTED PREY CAPTURE
}

\author{
C. Drew Foster ${ }^{1,2}$ and Patrick Martin ${ }^{1}$
}

\begin{abstract}
Many snakes employ tail movements to attract prey, but this behavior is rare in lizards. Use of caudal movements to distract prey, however, is rare in all squamates. Recently, caudal movements in a Sceloporus occidentalis individual immediately prior to attempted prey capture were documented. We supplement this sole documentation of caudal movements in S. occidentalis with additional field observations. Additionally, video footage of the behavior was recorded on 2 occasions. From these additional observations, we hypothesize that this behavior might serve to distract prey.
\end{abstract}

Key words: caudal luring, caudal distraction, Sceloporus occidentalis, western fence lizard.

Squamate tails are important structures that serve several functions in defense (e.g., lizard tail autotomy [Arnold 1988], snake tail rattling/ vibrating [Greene 1973]), aggression (e.g., tail whipping) and feeding. Caudal luring, the use of tail movements to attract prey items, is prevalent among a variety of snakes (Heatwole and Davison 1976, Tiebout 1997) but has been documented in only 2 species of lizard (Pygopodidae: Lialis burtonis [Murray et al. 1991] and Scincidae: Leiolopisma telfairii [Pernetta et al. 2005]). Caudal distraction, the use of tail movements to shift the attention of prey away from the head and toward the caudal end of a predator, is rare in all squamates (but see Mullin 1999).

Recently, Foster (2006) described the 1st account of potential caudal luring or distraction of prey by the western fence lizard (Sceloporus occidentalis). Additional observations were made of several individuals on the grounds of the Santa Barbara Zoo, Santa Barbara County, California (an area ca. 12 ha). Several factors suggest this novel behavior might constitute caudal distraction. Herein, we supplement Foster (2006) with additional field observations and further discuss this novel behavior. Additionally, digital video footage of this behavior was recorded in the field using a Kodak Easyshare P850 Zoom ${ }^{\circledR}$ digital camera. The footage is available from CDF and can be viewed online. In one case, when possible to do so accurately, video was examined through frame- by-frame analysis to quantify the number of tail movements per second.

On 25 June 2006 at 10:15, we observed an adult (11 g, $7.0 \mathrm{~cm}$ SVL, $9.1 \mathrm{~cm}$ tail length) male $S$. occidentalis moving around on the ground in some grass and bare dirt $\left(34^{\circ} 25^{\prime} 5^{\prime \prime} \mathrm{N}\right.$, $119^{\circ} 39^{\prime} 57^{\prime \prime} \mathrm{W}$, datum: WGS 84; elevation $10 \mathrm{~m}$ ). Several (ca. 10) unidentified species of flies were moving around the area, and the lizard suddenly caught sight of one in flight. When the insect landed on the ground, the lizard immediately ran toward it and stopped ca. 20 $\mathrm{cm}$ away. While looking at the fly, the lizard began to move the last 3-4 cm of the tail from side to side while keeping the rest of the body motionless. The tail shaking was slow and with intermittent "flailing," more similar to rat snake caudal movements associated with prey distraction (S. Mullin personal communication; see Mullin 1999) than to movements associated with colubrid snake defensive behaviors (sensu Foster 2006). We observed this individual exhibiting this behavior during 3 attempted, and unsuccessful, prey captures of 2 different flies. Tail movement durations were between 5 and 15 seconds, after which the lizard would lunge at and attempt to capture and consume the fly. During the 10-minute observation time interval, we also observed this fence lizard successfully capture and consume a smaller unidentified and flightless prey item on a nearby log without exhibiting tail movements. After this series of observations, the lizard was

\footnotetext{
${ }^{1}$ Santa Barbara Zoo, 500 Niños Drive, Santa Barbara, CA 93103. mail.com

Present address: Lincoln Park Zoo, Regenstein Small Mammal and Reptile House, 2200 North Cannon Drive, Chicago, IL 60614. E-mail: cucdf4@hot-
} 
captured, weighed, and measured before being released at the site of capture. Although we made this observation in close proximity to the one appearing in Foster (2006), distinct color differences between the 2 animals led us to believe that different individuals were involved. Multiple individuals of similar size have been observed in this immediate area simultaneously.

On 26 June 2006 at ca. 09:00, we videotaped an S. occidentalis resting on a branch. When a flying insect landed on a blade of grass causing it to move (just over 6 seconds into the video and again at 9 seconds), the lizard immediately directed its attention toward the insect and began moving the tip of its tail. After the 1st attempted prey capture was unsuccessful, the lizard kept watch on the prey and tail movements became more pronounced. This individual also supplemented tail movements with stalking movements toward the prey. In this case, however, after landing on the ground, the insect was walking away from the lizard. After several unsuccessful capture attempts, the lizard ceased this behavior and retreated to a log shelter. Video footage of this episode is available at http://www.youtube.com/ $\mathrm{v} / \mathrm{fbQk} 011 \mathrm{jmMg}$

On 29 June 2006 at ca. 09:00, CDF videotaped a smaller individual (ca. $6 \mathrm{~cm} \mathrm{SVL}$ ) in this same area (ca. $5 \mathrm{~m} \mathrm{~W}$ of the 26 June 2006 observation). Upon catching sight of an unidentified fly species walking around on the ground (just off screen in the video, ca. $20 \mathrm{~cm}$ in front of the lizard), the lizard began moving its tail tip (ca. last $3 \mathrm{~cm}$ ) from side to side at ca. 9.3 undulations $\cdot \mathrm{s}^{-1}$ for 6.7 seconds. Tail movements ceased for ca. 1 second and began again with 2 large, wide-arcing motions directed toward the right side of the body, averaging ca. 6.8 undulations $\cdot \mathrm{s}^{-1}$ and lasting for ca. 2.5 seconds. During this time, tail movements were more sporadic with intermittent flailing; they completely ceased immediately before an attempted and unsuccessful prey capture. Video footage of this episode is available at http://www .youtube.com/v/rc0nY2_53Wk

On 16 July 2006 at ca. 14:00, we observed a smaller individual (between 4 and $5 \mathrm{~cm} \mathrm{SVL}$ ) sitting in the fissure of a rock ca. $15 \mathrm{~cm}$ off the ground $\left(34^{\circ} 25^{\prime} 09^{\prime \prime} \mathrm{N}, 119^{\circ} 39^{\prime} 54^{\prime \prime} \mathrm{W}\right.$, datum WGS 84 ; elevation $12 \mathrm{~m}$ ). When it noticed a potential prey item on the ground, it emerged slightly from the fissure and began moving the tail tip (last $2-3 \mathrm{~cm}$ ). The duration of tail movements lasted just over 3 seconds, much shorter than all previously observed episodes. After an unsuccessful capture attempt, the lizard ran back to the rock. Again watching the prey, it began moving its tail for ca. 10 seconds before disappearing into the fissure.

These tail movements are apparently common (we observed them on numerous occasions without spending hours observing lizards) and might represent a displacement activity, a contextually functionless behavior releasing nervous tension in a stressful or anticipatory situation (see Tinbergen 1952). Insect vision is acute enough to detect these movements (Bouzerdoum 1993), however, and such movements might serve to lure or, more likely, to distract prey. We never observed tail movements attracting insects (i.e., insects were never observed moving toward the tail) as might be expected with caudal luring. Sceloporus occidentalis feeds almost exclusively on invertebrates, as was the case in all of our observations. Invertebrate prey would likely not be attracted to vermiforms (what the tail is often understood to represent in true caudal luring), but tail movements might serve to redirect the attention of invertebrate prey away from the business end (anterior portion) of the predator. The position of the tail relative to the lizard's head is also not indicative of caudal luring. Mullin (1999) indicated a greater distance separating the head and the tail in rat snakes when distracting than that reported for snake species caudal luring. Similiarly, S. occidentalis individuals displaying caudal movements did not hold the tail adjacent to the head, but kept it aligned with the body's axis, displaced just laterally in most instances. Lastly, the speed of $S$. occidentalis tail movements observed herein was much faster than caudal movements associated with luring (personal observation) and more indicative of distraction. Caudal distraction has not been reported for any lizard species, but tail movements described herein likely serve to focus the prey's attention on the caudal end of the predator, possibly enhancing successful prey capture by S. occidentalis (although we were unable to document successful predation involving caudal distraction).

Many questions remain surrounding the described caudal movements by S. occidentalis. Does this behavior actually improve successful prey captures? If this behavior does 
improve prey capture, are lizards that employ it larger? Do individuals of all sizes and age classes employ this behavior? Because we observed 1 individual moving its tail when attempting to capture flies, but not when feeding on another flightless invertebrate, is this behavior elicited only by certain prey (e.g., flying) or is it equally common across all prey taxa? Does the prey actually respond to the tail movement of the lizard (e.g., move toward the tail)? Future work should investigate these and other questions in attempts to determine what purpose, if any (Tinbergen 1952), these reported caudal movements serve. However, it appears that $S$. occidentalis might employ caudal movements to distract prey items, making this the 1st lizard species to employ caudal movements to distract prey.

We thank Alan Varsik of the Santa Barbara Zoo for providing the digital camera used to capture the video footage of this behavior.

\section{Literature Cited}

ArNold, E.N. 1988. Caudal autotomy as a defense. Pages 235-273 in C. Gans and R.B. Huey, editors, Biology of the Reptilia. Volume 16. Alan R. Liss, New York.
Bouzerdoum, A. 1993. The elementary movement detection mechanism in insect vision. Philosophical Transactions: Biological Sciences 339:375-384.

Foster, C.D. 2006. Sceloporus occidentalis (western fence lizard). Caudal movement. Herpetological Review 37:471-472.

Greene, H.W. 1973. Defensive tail display by snakes and amphisbaenians. Journal of Herpetology 7:143-161.

Heatwole, H., and E. Davison. 1976. A review of caudal luring in snakes with notes on its occurrence in the Saharan sand viper, Cerastes vipera. Herpetologica 32:332-336.

MulLin, S.J. 1999. Caudal distraction by rat snakes (Colubridae, Elaphe): a novel behavior used when capturing mammalian prey. Great Basin Naturalist 59:361367.

MurraY, B.A., S.D. Bradshaw, and D.H. Edward. 1991. Feeding behavior and the occurrence of caudal luring in Burton's pygopodid Lialis burtonis (Sauria: Pygopodidae). Copeia 1991:509-516.

Pernetta, A.P., T.N. Ross, And C.G. Jones. 2005. Leiolopisma telfairii (Telfair's skink). Caudal luring. Herpetological Review 36:320-321.

Tiebout, H.M., III. 1997. Caudal luring by a temperate colubrid snake, Elaphe obsoleta, and its implications for the evolution of the rattle among rattlesnakes. Journal of Herpetology 31:290-292.

Tinbergen, N. 1952. "Derived" activities: their causation, biological significance, origin, and emancipation during evolution. Quarterly Review of Biology 27:1-32.

Received 27 September 2007 Accepted 8 January 2008 